\title{
The Tuberculosis Problem
}

\author{
By RUSSEll E. TEAGUE, M.D.
}

In almost all of its aspects, the rapidty changing picture of the tuberculosis problem in the United States presents one of the most profound sociobiological phenomena, if not the most interesting development, in the entire field of medicine and epidemiology. It is significant, if not paradoxical, that, as many aspects of the disease decline or diminish at an accelerated rate, the program for control continues to expand.

\section{Decline in Infection Rate}

Results of tuberculin tests of sample populations in Philadelphia in 1949 seem to indicate that today individuals are being infected with the tubercle bacillus at an average rate of less than 1 percent per year, or one new tuberculosis infection per 100 person-years of life.

Data from three studies at the Henry Fhipps Institute in Philadelphia bear out this observation. In these studies, children in three large high schools were tested at 10 -year intervalsin 1929, 1939, and 1949. In 1929 the average rate of conversion to the first test dose of tuberculin was 5.3 per 100 person-years; in 1939, this rate was 2.7 ; and in 1949, less than 1 . At the average age of 16 years, in all three studies, the percentages of children who were positive to the first test dose of tuberculin were: 1929 , 84 percent; 1939, 43 percent; and 1949, 16 percent.

Dr. Teague is secretary of health, Commonwealth of Pennsylvania. This paper was presented before the forty-eighth annual meeting of the National Tuberculosis Association in Boston, May 2\%, 1952.
If conversion to the first test dose of tuberculin indicates acquired tuberculous infection or exposure to the tubercle bacillus, the average individual living in Philadelphia under the 1929 rate would have had a new experience with the tubercle bacillus at least three times during his life, whereas if he had lived under the 1949 rate, the chance that he would not be infected at all would be about 50 percent.

It is being recognized and widely accepted that evidence of infection-a positive tuberculin test and especially a recent conversionbecomes more helpful and significant today than in the past. This is true from the viewpoint of the epidemiologist, the diagnostician, and the therapist.

\section{Morbidity}

A compilation and preliminary analysis of tuberculosis reports from the States, recently prepared by the Division of Chronic Disease and Tuberculosis of the Public Health Service, provides a source for morbidity data for 1951.

According to this report, 118,414 new cases were reported in the United States in 1951. Although this figure may not be final for the year, it represents a decline of less than 3 percent from the number reported for 1950, and 12.3 percent from the 1947 total. The average annual decline in reported cases since 1947 is 3.07 percent per year.

In view of the intensified case finding during this period, these data are encouraging. The reported case rates for the white and the nonwhite cases were 68.1 and 165.3 per 100,000 population, respectively. For white and for nonwhite males the respective rates were 86.6 and 194.8 ; for white and for nonwhite females, 49.9 and 136.1 . 
There were four new cases reported in 1951 for each tuberculosis death reported, an improvement in the ratio when compared to 2.8 cases per death in 1947, 3.1 in 1948, 3.4 in 1949, and 3.6 in 1950 . The case-death ratio remains higher for whites than for nonwhites and higher for females than for males.

\section{Mortality}

In 1950 there were 33,577 deaths from tuberculosis, or 2.3 percent of the total deaths from all causes for that year. Compilations of the total number of deaths reported for 1951 have not been completed, but, based on a 10-percent sample study made by the National Office of Vital Statistics, Public Health Service, the decline in the number of deaths from tuberculosis from 1950 to 1951 was about 11 percent for the country.

The number of deaths from tuberculosis, as well as evidence of infection and morbidity, is dropping faster in the younger age groups and in females than in older males. In 1952, 75 percent of the population of many sanatoriums were males, most of them in the advanced age group.

\section{Longevity of Pulmonary Tuberculosis Patients}

My recent life table study of the longevity of all clinic patients diagnosed as having active tuberculosis at the Henry Phipps Institute in the 20-year period between 1926 and 1945 indicates that the average longevity of these patients is 5.9 years. While the whites lived 11.2 years, the average length of life of the nonwhites was 3.5 years.

The cases diagnosed in the minimal stage averaged 25.1 years of life after diagnosis, those in the moderately advanced stage, 9.9 years, while those diagnosed in the far-advanced stage averaged only 1.1 years.

There was no difference in the case fatality rates when the number of cases in the first 10 year period was compared with those in the latter 10-year period. With recent improvements in therapy, however, marked improvement in the case-fatality rates of the patients diagnosed in 1952 would be expected.
Despite the improved picture of the disease, activities directed toward meeting the problem continue to increase.

\section{Case Finding}

In 1951 , reports indicate that about $13,000,000$ chest X-rays were made by States and by the agencies reporting to them. This amounts to 8.2 percent of the total population of the country. In three States the number of X-rays taken amounted to more than 20 percent of their population last year.

Recent studies on familial susceptibility and resistance emphasize the importance of heredity in epidemiology and point out that in the future case finding may very well be directed toward continued medical supervision of the blood relatives of known cases, wherever they may reside.

\section{Isolation and Treatment}

Since the prevention of this disease is directly proportional to the number of patient-days of effective islation, it is encouraging that more beds are becoming available each year for tuberculosis patients. More chest surgery and chemotherapy should eventually result in shorter periods of hospitalization and thereby permit more beds for more patients.

The problem of isolation of the "good chronic" patient has not yet been solved in most areas, and agencies and health administrators are concerned with this problem to an increasing degree.

The management of the recalcitrant infectious patient is being met in many areas by compulsory isolation procedures, and there is evidence of more widespread application of these techniques.

Public health administrators and sanatorium superintendents are plagued with a shortage of personnel, especially nurses, and the trend toward using nonprofessional aides is increasing.

\section{Rehabilitation}

Rehabilitation programs for tuberculous patients have not been developed universally. 
With a few outstanding exceptions, this part of the problem is yet to be expanded generally.

\section{Immunization}

Three States have provided a BCG immunization program for medical students, nurses, and children of infected families. A number of other areas are using vaccination on a more limited basis. The wide-scale use of mass BCG vaccination will undoubtedly be limited to those parts of the world where infection is high and other facilities for control are limited.

\section{The Future}

In recent years advances have been made in the fundamental knowledge of tuberculosis in the fields of pathology, bacteriology, immunology, epidemiology, public health techniques, therapy, genetics, and social services, and the total expansion in the whole field of tuberculosis research is heartening. Barring a national catastrophe, it is not illogical to assume that in one more generation the "great white plague" will no longer be a major public health problem in the United States, but this does not mean that we can ever relax our vigilance.

On the other hand, the prevention program must be intensified. Then education of the layman will be more difficult and it will cost much more to find the unknown case, but there will be less expense for tuberculosis hospital beds, and more institutional space will be available for isolation of the "good chronics" that re- main. More attention will be paid to the hereditary factors in infection. Greater efforts will be given to preventing the entry of tuberculous patients from parts of the world where high rates prevail, and concern may be expressed about the danger of our unexposed, tuberculin-negative population even visiting in areas of high infection. This concern may not be justified and only further studies will give the answer.

\section{REFERENCES}

(1) Long, Esmond R.: Our changing perspective in tuberculosis. Philadelphia Med. 45: 1479-1485 (1950).

(2) U. S. Public Health Service: Case finding, tuberculosis, morbidity and other data. A compilation of data on the annual and semi-annual tuberculosis reports, 1951. Mimeographed.

(3) Teague, Russell E., and Placentra, Ersilia: The length of life of tuberculosis patients in relation to the epidemiology of the disease. (Read St. Louis meeting APHA, 1951.) In press.

(4) Puffer, Ruth R., Zeidberg, L. D., Dillon, Ann, Gasso, R. S., and Hutcheson, R. H. : Tuberculosis attack and death rates of household associates. The influence of age, sex, race, and relationship. Am. Rev. Tuberc. 65: 111-127 (1952).

(5) Seibert, Florence B., Hetherington, H. W., Landis, H. R. M. : University of Pennsylvania, Henry Phipps Institute Reports, 1930, 1940, 1950.

(6) Long, Esmond R.: Recent advances in fundamental knowledge of tuberculosis. In Proceedings of the Conference of Tropical Medicine and Malaria. 6: 179-186 (1948).

(7) Long, Esmond R.: Advances in tuberculosis research. Transactions of the National Tuberculosis Association Forty-seventh Annual Meeting, 1951, pp. 391-396.

\section{Children With Heart Disease Aided}

The third in a network of such services in the country, facilities at the Children's Memorial Hospital, Chicago, Ill., will be used to aid children with serious heart conditions, such as "blue babies" whose condition can be helped by surgery, through a special grant by the Children's Bureau of the Federal Security Agency.

This facility will serve Michigan, Ohio, Kentucky, Minnesota, Wisconsin, Indiana, North Dakota, South Dakota, Nebraska, Iowa, Kansas, and Missouri. Illinois already provides service for children under their crippled children's program.

Two other such centers are already in operation in Connecticut and California. Other programs are planned in the East and Southwest. 